\title{
Use of climate information in soybean farming on the Argentinean pampas
}

\author{
Federico E. Bert ${ }^{1,2, *}$, Guillermo P. Podestá ${ }^{3}$, Emilio H. Satorre ${ }^{1,2}$, Carlos D. Messina ${ }^{4}$ \\ ${ }^{1}$ Cátedra de Cerealicultura, Facultad de Agronomía, Universidad de Buenos Aires, PO Box C1417DSE, \\ Av. San Martín 4453, Buenos Aires, Argentina \\ 22Área de Tecnología, AACREA (Asociación Argentina de Consorcios Regionales de Experimentación Agrícola), \\ PO Box C1041AAZ, Sarmiento 1236, Buenos Aires, Argentina \\ ${ }^{3}$ Rosenstiel School of Marine and Atmospheric Science, University of Miami, 4600 Rickenbacker Causeway, \\ Miami, Florida 33149, USA \\ ${ }^{4}$ Pioneer Hi-bred International, Global Product Design, Du Pont Agriculture \& Nutrion, 7300 NW 62nd Avenue, Johnston, \\ Iowa 50131, USA
}

\begin{abstract}
The availability of enhanced climate forecasts offers the potential for farmers to improve responses to climate variability. However, few studies have demonstrated actual effective uses of climate forecasts. Through interaction with regional agricultural experts, we evaluated the opportunities and constraints involved in the use of climate information in decision making regarding soybean farming in the Argentinean pampas. Our results showed that opportunities exist for the successful application of climate information, but consistent with previous research, there is a need to consider the broad and complex context influencing decisions, since climate is just one of the many factors affecting farmers' decisions. More importantly, we showed that adaptive management strategies proposed by experts in response to hypothetical climate scenarios produced diverging economic outcomes (both positive and negative). We hypothesized that inconsistency of the observed results could be due to a poor understanding by the agricultural experts of the impacts on regional climate of global climate signals (e.g. a given ENSO phase). An alternative hypothesis was that crop consultants had difficulties in anticipating the agronomic outcomes of management decisions made in response to a given climate forecast. Further research is needed to elucidate to what extent these hypotheses are valid. However, our results suggest that the mere availability of climate forecasts will not necessarily benefit growers. In order for there to be an improvement in the use of seasonal forecasts, appropriate interventions are necessary to enhance decision makers' understanding of the sources and impacts of climate variability, and of the consequences of different responses to a range of climate scenarios.
\end{abstract}

KEY WORDS: ENSO - Climate forecasts · Decision making $\cdot$ Descriptive studies $\cdot$ Regional experts

Resale or republication not permitted without written consent of the publisher

\section{INTRODUCTION}

Recent advances in the understanding and monitoring of the oceans and atmosphere have made it possible to anticipate seasonal climate anomalies with demonstrable skill for some regions, seasons and circumstances (Murphy et al. 2001, Barnston et al. 2005). This predictability is linked mostly to the ability to anticipate anomalies in sea-surface temperatures (SST) associated with the El Niño-Southern Oscillation (ENSO) phenomenon (Mason et al. 1996). In turn, SST predictions, together with general atmospheric circulation models, can be used to predict seasonal total precipitation and mean temperature for many regions of the world (Goddard et al. 2003, Mason et al. 1999). Seasonal climate outlooks with lead times of up to 
12 mo are currently being disseminated for several world regions (Mason et al. 1999).

With improvements in regional climate forecasts comes the potential for improved management of agricultural production (Hammer et al. 2001, Hansen 2002, Meinke \& Stone 2005). It is often expected that seasonal climate forecasts should allow farmers to make proactive management decision, mitigating adverse conditions or, alternatively, taking advantage of favorable environments. Indeed, studies in different agricultural systems around the world have found potential benefits from the incorporation of climate forecast into the decision-making process (Meinke \& Stone 1997, Messina et al. 1999, Mjelde et al. 1999, Jones et al. 2000, Podestá et al. 2002). Despite the apparent benefits of seasonal climate forecasts, adoption of this technology has occurred more slowly and in a more haphazard way that was envisaged (Stern \& Easterling 1999, Phillips et al. 2001, Meinke \& Stone 2005).

Several theoretical and practical obstacles may be involved in the slow uptake of climate forecasts (Pulwarty \& Redmond 1997, Orlove \& Tosteson 1999, Broad \& Agrawala 2000, Patt \& Gwata 2002). Some of these obstacles are inherent in the climate system's complexity: forecasts typically have coarse spatial and temporal resolution; not all relevant climate variables can be predicted; the skill, accuracy and reliability of forecasts is not well characterized or understood; and contradictory predictions may coexist. Other obstacles include procedural, institutional, and cognitive difficulties in receiving and understanding information, or the ability and willingness of decision-makers to modify their actions (Patt \& Gwata 2002). Furthermore, the obstacles may induce a range of undesired responses: users may ignore the forecasts or any concomitant advice, may not change decisions in response to forecasts, or may change decisions in a counterproductive way (Patt \& Gwata 2002).

It is increasingly clear that the mere availability of a climate forecast (regardless of how accurate and well communicated) is not sufficient to ensure that agricultural economic outcomes will improve. Closing the gap between the availability of climate forecasts and their effective application depends, among other things, on a firm understanding of users' needs and decisionmaking processes, and of the broader context in which decisions are made (Stern \& Easterling 1999, Eakin 2000, Roncoli et al. 2001, Stewart et al. 2004, Bert et al. 2006). The best way to develop a realistic understanding of decisions and their context is to interact with actual or potential users of climate information (Hammer et al. 2001, Stewart et al. 2004).

Most studies of the use of climate forecasts have relied on prescriptive models that identified optimal decisions in response to a prediction (Stewart 1997,
Wilks 1997, Stern \& Easterling 1999). However, this approach often involves assumptions about decisionmakers' behavior and their context that are oversimplifications of real systems. Prescriptive studies, therefore, may provide unrealistic (or overly optimistic) estimates of the usefulness of climate forecasts. An alternative and complementary approach is descriptive analysis, where the goal is to identify how users actually decide, rather than what they should decide. This approach yields an estimate of the actual value of the forecasts to a real user who may or may not use information in an optimal fashion (Stewart 1997).

The present study was based on a describe analysis. The objective was to conduct a participatory assessment of the potential of seasonal climate forecasts to enhance agricultural decision making in soybean farms in the Argentine pampas, one of the most important agricultural regions in the world. The study involved 2 main stages. (Stage 1) In close collaboration with a group of 17 regional technical experts, this stage identified soybean production decisions, their timing, and the influence of climate and climate information on these decisions. In addition, the ability of decision makers' to modify soybean management in response to climate forecasts was assessed, and a realistic range of viable adaptive responses was identified. (Stage 2) In this stage we assessed the potential economic outcomes of modifying production decisions in response to climate forecasts. Rather than using prescriptive or 'optimal' responses, we used actual management changes proposed by the regional experts.

\section{CASE STUDY}

This research focuses on soybean farming on the Pampas of central-eastern Argentina (Hall et al. 1992). In particular, we focus on the 'rolling pampas', the most productive sub-region of the pampas, which encompasses the northern part of the province of Buenos Aires and the southern part of the province of Santa Fé. The rolling pampas is the main soybean production area in Argentina and has the longest history of crop production. In addition to soybeans, important crops in the region include maize and a wheat-soybean double crop. Hall et al. (1992) gives a thorough description of the climate, soils, and crop production systems in the region.

The pampas region shows a strong ENSO signal, particularly in the southern spring and summer, coinciding with the growing season of the most important crops (Ropelewski \& Halpert 1987, 1989, 1996, Grimm et al. 2000, Montecinos et al. 2000). During these months, warm (cold) ENSO events tend to be wetter (drier) than neutral years. In neutral years, average 
precipitation tends to be very close to climatological values. Because the vast majority of agriculture in the Pampas is rainfed, ENSO-related climate variability influences crop yields (Podestá et al. 1999, Travasso et al. 2003). In particular, soybean yields decrease in response to dry conditions that occur more frequently during cold events (La Niña years). In contrast, rainier conditions associated with warm events (El Niño years) do not appear to significantly affect soybean yields (Podestá et al. 1999).

Current soybean farming in Argentina offer an interesting case study for the use of climate information. First, the modern production technologies currently used in the Pampas give farmers a broad spectrum of options to tailor crop management to an expected climate scenario. Second, in recent years, the standard practice of crop rotation has been increasingly replaced by soybean monoculture (Satorre 2005). About half of the cropped area in the Pampas is currently planted with soybeans, which represents about $20 \%$ of the total economic value of Argentine exports. The dependence of a considerable proportion of agricultural income on a single activity increases the vulnerability of the Argentine society to shocks or surprises, such as widespread climate anomalies or price fluctuations. It is important to explore whether the effective use of climate information might reduce the impacts of climate fluctuations, thus helping to decrease the vulnerability of the Argentine economic system.

\section{APPROACH AND METHODS}

The participation of potential users of climate forecast information in studies of the adoption of this information is critical. Participatory approaches are important because the accuracy and impacts of climate forecasts are not yet obvious to potential users, and climate scientists are still not fully aware which attributes of forecast information would be most useful for recipients (Stern \& Easterling 1999). Therefore, an open and repeated interaction among researchers, analysts and decision-makers may lead to a better balance between information demand and supply, as well as an enhanced appreciation and awareness of the capabilities and limitations of this information (Hammer et al. 2001).

In this research, we worked with a group of regional experts: technical advisors from AACREA (Asociación Argentina de Consorcios Regionales de Experimentación Agrícola; www.aacrea.com.ar), a non-profit farmers' organization. AACREA members join groups of 7 to 12 farmers. Each group has a technical advisor (funded by group members) who provides information and advice to group members and coordinates exchanges both between and within the group. We focused on 2 AACREA regions (north of Buenos Aires and south of Santa Fé) as representative of soybean farming in the Rolling Pampas. In these 2 areas, there are about 150 AACREA farmers in 21 groups supported by 17 technical advisors (Fig. 1). Every year, AACREA farmers in the target region crop about 280000 ha, of which almost 75000 ha are allocated to soybean.

The activities undertaken in this work were organized into 2 separate stages. In the first stage, we worked with the advisors to describe a set of decisions related to soybean production. By means of questionnaires, a decision exercise, and extended discussions we elicited information about the decision-making context, the role of climate information in decisionmaking, and the range of viable adaptive responses to different climate scenarios. In the second stage, we used simulation models to assess the outcomes of adaptive responses to climate forecasts. The following sections provide details about each stage.

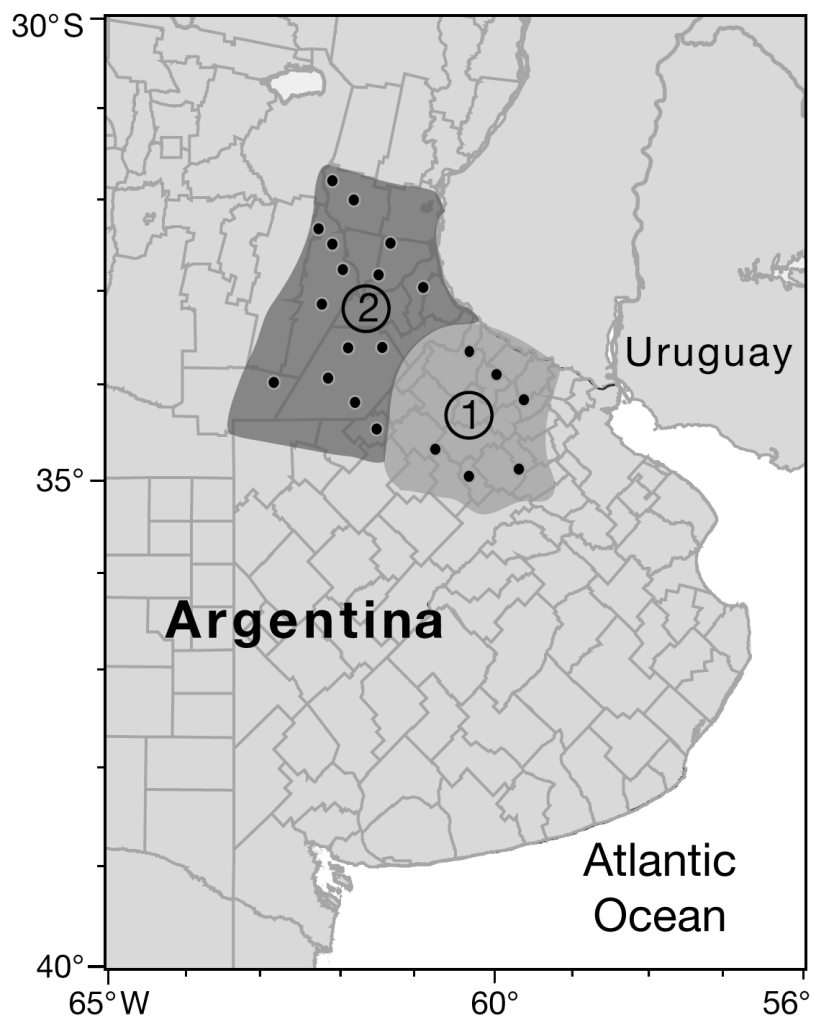

Fig. 1. The study area (Asociación Argentina de Consorcios Regionales de Experimentación Agrícola [AACREA] regions): (1) north Buenos Aires province; and (2) south Santa Fé province. Black dots: approximate geographic center of each of the 21 AACREA groups involved in the study $(7$ to 12 farmers make up each group). We worked with the 17 technical advisors to the groups. Boundaries within Argentina: counties 


\subsection{Stage 1: Elicitation of information}

In this stage we worked in close interaction with the advisors from the 2 AACREA regions targeted (Fig. 1). We chose to work with advisors rather than farmers because: (1) advisors directly or indirectly influence many farm management decisions, particularly those related to production; (2) their perceptions and opinions reflect concerns from a large number of farmers; and (3) advisors are key intermediary agents who act as trusted facilitators across the research-practice continuum

We conducted 2 rounds of interactions with the advisors. In a first meeting, we aimed to understand the decisions involved in soybean production. In a second meeting, we attempted to clarify and enhance our understanding of the decision-making process elicited during the first meeting. This meeting involved open, extended discussion with advisors, as well as observation of the regular monthly advisors' meeting.

A questionnaire and a decision exercise were completed individually by the advisors during the first meeting. The questionnaire included semi-open questions about 6 specific management decisions related to soybean production: (1) land area allocated to soybeans; (2) sowing date; (3) genotype selection; (4) row spacing; (5) sowing density; and (6) phosphorus fertilization rate. An initial set of questions attempted to rank the influence of various contextual factors (identified in earlier interactions with AACREA advisors and farmers) on decisions about soybean management. These factors included the expected climate during the crop cycle. A second set of questions elicited user needs for climate information in soybean production.

After the questionnaire, the advisors completed a decision exercise designed to identify a realistic range of management options that might be adopted in response to different climate scenarios. Advisors were given a hypothetical farm for which they had to make recommendations on the 6 management decisions listed above. In the first part of the exercise, decisions had to be made using summary information about climate conditions in the last $10 \mathrm{yr}$. These decisions are referred to as 'climatological management' (CM) decisions, i.e. management decisions were based on climatological information alone. During the second part of the exercise, the advisors were presented with 3 different climate forecasts that included: (1) an El Niño event; (2) a La Niña event; and (3) a quantitative precipitation forecast (QPF) based on an actual forecast emitted by a local public agency at the moment of the exercise. This forecast anticipated higher that normal precipitations during November and December, and lower than normal rainfall in January and February. Information about forecast accuracy was neither pre- sented nor discussed at any time during the exercise. Advisors were given the option of adjusting the previously selected CM decisions for each of the 3 forecasts.

\subsection{Stage 2: Economic outcomes of climate forecast use}

In the second stage of the study, we used a biophysical crop model and realistic cost estimates to evaluate the farm-wide agronomic and economic outcomes of management decisions selected in response to the different climate scenarios. To this end, we simulated yields and net returns of all management options selected by the advisors for each climate scenario presented in the decision exercise. Below we describe the details of the simulations and the calculation of farmwide economic results.

\subsubsection{Simulations}

The CROPGRO model (Boote et al. 1998) within the Decision Support system for Agrotechnology Transfer package (Jones et al. 1998) was used to simulate soybean yields. This model has been calibrated and validated in the pampas (Meira \& Guevara 1997, Mercau et al. 2007). This model simulates the daily growth and development of soybean as a function of inputs such as daily weather, crop management, genetic information, and soil characteristics. Crop and soil parameters were available from our previous research in the study area (Bert et al. 2006, authors' unpubl. data).

Obtaining long-term daily weather data for use as input to crop models is often difficult or expensive. An alternative solution is the use of stochastic weather generators which can produce long series of synthetic daily weather with statistical characteristics consistent with those of historical data. In this work we used synthetic series of daily weather variables produced by a weather generator based on the approach described by Richardson (1981) and parameterized conditionally on ENSO phase (Grondona et al. 2000). Four synthetic series of daily weather representing the climate scenarios involved in the decision exercise were used in the simulations: one series representing climatological conditions (1750 yr, with the historical proportion of El Niño, La Niña and neutral years), 2 series representing respectively El Niño and La Niña events (1000 synthetic years in each series), and a series representing the QPF (180 yr). This QPF scenario was built by selecting from the synthetic series representing climatological conditions those years with precipitations in the upper tercile for November and December and in lower tercile for January and February. 
We defined 16 different soybean management combinations (or treatments) that encompassed the options selected by the advisors during the exercise. The options considered included: (1) 2 soybean varieties (DM4800, long cycle; N3901, short cycle); (2) 4 planting dates (early planting on 15 October, normalearly planting on 1 November, normal-late planting on 15 November, and late planting on 30 November) and; (3) 2 row spacings ( 0.52 and $0.26 \mathrm{~m}$ ). A representative soil for the region (a typical Argiudoll) was used. Soil conditions at sowing time were set to values frequently found in the region. Soybean yields were simulated for the 16 crop management treatments and the 4 climate scenarios listed above.

\subsubsection{Economic outcomes}

Simulated soybean yields were used to compute net profit for each soybean treatment. The net profit of a treatment $(\pi)$ was computed as the difference between gross income and fixed and variable costs. Gross income was calculated as the product of simulated yield $\times$ soybean price (average of last $5 \mathrm{yr}$ ). Fixed production costs were independent of soybean yields and included: seed, labor, and agrochemicals. Variable costs were a function of soybean yield and included harvest costs, transportation costs, and sales tax and commissions.

The production strategies proposed by advisors for the hypothetical farm always included a combination of soybean treatments (i.e. more than one genotype, sowing date, etc.). For this reason, the farm-wide profit for a strategy was computed by combining profits for each of the 16 treatments:

$$
\pi_{s}=\sum_{t=1}^{16} \pi_{t} \times p_{t}
$$

where $\pi_{s}$ is the net profit (US dollars [\$] ha ${ }^{-1}$ ) of strategy $s, \pi_{t}$ is the net profit of treatment $t$ and, $p_{t}$ is the proportion of treatment $t$ in strategy $s$.

The expected value of climate information (EVOI) was estimated as the difference between the net profits of the strategy adopted by advisors in response to seasonal climate forecasts on year $i\left(\pi_{s, i}\right)$ and the net profit of the CM strategy (selected without climate forecasts) on synthetic year $i\left(\pi_{c, i}\right)$, averaged over the $n$ synthetic years for each climate scenario:

$$
\mathrm{EVOI}=\frac{1}{n} \sum_{i=1}^{n}\left(\pi_{s, i}-\pi_{c, i}\right)
$$

By considering the difference between average net profits rather than a difference in utilities, we are assuming that decision-makers are risk-indifferent. This assumption is reasonable because we are mainly interested in using EVOI to compare strategies.

\section{RESULTS}

\subsection{Elicited information}

4.1.1. Timing for planning and execution of decisions

Soybean production decisions are made during a period that starts several months prior to sowing (i.e. March) and ends with sowing in late October or early November (Table 1). When harvest of the previous cycle's summer crops is completed (March to April), preliminary land allocation decisions are made for the following season. These land allocation plans are executed as the sowing of each chosen crop occurs. The area allocated to soybean is defined once maize planting is completed (September to early October). Preliminary soybean management decisions are made 2 to 3 mo prior to sowing (i.e. July to August) but are often revised up to the period preceding planting. Some of these decisions (e.g. genotypes to be used, fertilizer type and amount) must be defined at least a couple of weeks prior to sowing because of logistic constraints.

\subsubsection{Factors influencing production decisions and the role of expected climate}

According to the advisors interviewed, a broad suite of factors influence soybean production decisions. Relevant factors, listed in Table 1, include: (1) factors related to the decision maker (e.g. target yield); (2) factors related to farm management (e.g. crop rotation scheme); (3) factors related to the farm (e.g. soil quality, farm financial situation); and (4) external environmental or socio-economic factors (e.g. price of cereals and oilseeds, expected climate). Most soybean-related decisions are simultaneously influenced by more than one factor, and the importance of a given factor varies with the specific decision considered (Table 1). Further, decisions may be influenced by factors that are important only in some situations (for some farms, or to some advisors). For instance, selection of genotypes could be restricted to those genotypes available in the farm (i.e. seed stored from the previous season).

Target yield and soil quality were the factors consistently ranked high for most decisions (Table 1). According to the advisors, the definition of a target yield (or profit) is the first step in the planning of a production cycle. Thus, the spectrum of viable decisions is initially conditioned by the target yield. Subsequently, decisions are fine-tuned and plot-level management is defined. Soil quality plays an important role at this stage, as it is the main source of environment $\times$ man- 
Table 1. Timing for planning and execution of soybean management decisions, and factors influencing each decision. Factors ranked ( 1 = highest importance) based on central value (median of the scores assigned by the advisors to the influence of each factor on each decision) and on variability of advisors' responses. 'Expected climate' is indicated in bold for each management decision. 'Factors potentially influencing decisions': those for which there was no consensus about importance among advisors (i.e. a high variability in scores)

\begin{tabular}{|c|c|c|c|}
\hline Decision & Timing & $\begin{array}{l}\text { Factors influencing } \\
\text { decisions (ranked) }\end{array}$ & $\begin{array}{l}\text { Factors potentially } \\
\text { influencing decisions }\end{array}$ \\
\hline $\begin{array}{l}\text { Land allocated } \\
\text { to soybean }\end{array}$ & $\begin{array}{l}\text { Planning: March-August } \\
\text { Execution: June-September }\end{array}$ & $\begin{array}{l}\text { 1. Fixed rotation scheme } \\
\text { 2. Soil quality } \\
\text { 3. Input costs } \\
\text { 4. Prices of cereals/oilseeds } \\
\text { 5. Risk of pest and/or diseases } \\
\text { 6. Expected climate }\end{array}$ & $\begin{array}{l}\text { Farm economic/financial } \\
\text { situation } \\
\text { Risk reduction }\end{array}$ \\
\hline Sowing date & $\begin{array}{l}\text { Planning: August-October } \\
\text { Execution: October-November }\end{array}$ & $\begin{array}{l}\text { 1. Target yield } \\
\text { 2. Risk reduction } \\
\text { 3. Soil conditions at sowing } \\
\text { 4. Soil quality } \\
\text { 5. Expected climate } \\
\text { 6. Risk of pest and/or diseases }\end{array}$ & Resource availability \\
\hline Genotype selection & $\begin{array}{l}\text { Planning: August-October } \\
\text { Execution: October }\end{array}$ & $\begin{array}{l}\text { 1. Target yield } \\
\text { 2. Soil quality } \\
\text { 3. Risk reduction } \\
\text { 4. Expected climate } \\
\text { 5. Risk of pest and/or diseases }\end{array}$ & $\begin{array}{l}\text { Resource availability } \\
\text { Soil conditions at sowing }\end{array}$ \\
\hline Row spacing & $\begin{array}{l}\text { Planning: August-October } \\
\text { Execution: October-November }\end{array}$ & $\begin{array}{l}\text { 1. Target yield } \\
\text { 2. Soil quality } \\
\text { 3. Soil conditions at sowing } \\
\text { 4. Expected climate }\end{array}$ & $\begin{array}{l}\text { Risk reduction } \\
\text { Resource availability }\end{array}$ \\
\hline Sowing density & $\begin{array}{l}\text { Planning: August-October } \\
\text { Execution: October-November }\end{array}$ & $\begin{array}{l}\text { 1. Soil quality } \\
\text { 2. Target yield }\end{array}$ & \\
\hline P fertilizer rate & $\begin{array}{l}\text { Planning: July-October } \\
\text { Execution: October }\end{array}$ & $\begin{array}{l}\text { 1. Target yield } \\
\text { 2. Soil quality } \\
\text { 3. Fixed rotations scheme }\end{array}$ & $\begin{array}{l}\text { Farm economic/financial situation } \\
\text { Input costs } \\
\text { Soil conditions at sowing } \\
\text { Prices of cereals/oilseeds }\end{array}$ \\
\hline
\end{tabular}

agement interactions (e.g. some crops/genotypes are preferentially allocated to high quality soils).

Expected climate during the crop cycle influences 4 of the 6 types of decisions considered in this study: land allocation, sowing date, genotype selection, and row spacing. In contrast, climate does not appear to influence decisions on planting density and fertilization. Even when climate is considered to influence decisions, often it is ranked as having relatively low importance (Table 1). However, follow-up discussions with regional advisors suggested that the actual importance of expected climate might be higher than indicated by the questionnaires, as climate may have indirect impacts through other relevant factors. A clear example is the effect of expected climate on the defin- ition of target yield (when climate expectations are poor, target yields may be adjusted downward). Similarly, climate expectations may influence farmers' concerns about potential yield losses due to pests and diseases and, consequently, trigger appropriate management changes. Further, the apparently low importance assigned by advisors to expected climate may be tied to the climatic context at the time the questionnaires were made (November 2004): the previous winter and the previous growing season had been climatically normal, and forecasts for the 2004-2005 cycle did not anticipate extreme climate conditions. The near-normal recent and expected climate context may have caused advisors to underestimate the importance of climate as a factor influencing decisions. 


\subsubsection{Advisors' climate information needs}

Advisors gave relatively low importance to expected climate as a factor influencing soybean production decisions. One possible explanation for the low ranking may be that the climate information deemed relevant or desirable is not available. To explore this possibility, we asked the advisors about their specific needs and desires for information about seasonal climate. The advisors indicated that precipitation forecasts at different stages of the crop cycle would help decisions on genotypes and planting dates and, with lesser consensus, row spacing (Table 2). Seasonal precipitation forecasts, however, were not considered useful to inform decisions on land allocation (constrained mostly by crop rotation, soil quality and commodity prices), sowing density, or fertilization. Predictions of November to February rainfall might allow adjustment of genotypes and planting dates to match (avoid) the coincidence of critical yield generation stages with favorable (unfavorable) climate conditions. Furthermore, advisors agreed that long (short) cycle varieties could show better performance if adverse (favorable) climate conditions were anticipated for this period. Weather forecasts (1 to $7 \mathrm{~d}$ into the future) during September to October are useful for the assessment of soil moisture conditions and thus for tactical decisions on the start of sowing operations. Although forecasts for precipitation in the fall are extremely desirable to manage harvest risks, predictability for this period is fairly limited. Finally, in contrast to the relevance of precipitation information for many decisions, the advisors considered that temperature forecasts have negligible practical utility in soybean production.

Much of the climate information considered relevant by the advisors is currently available for the study region. Precipitation in the Pampas during November to January is influenced by the ENSO phenomenon (Grimm et al. 2000, Montecinos et al. 2000). However, there is considerable variability in the precipitation signal within ENSO phases, which decreases the potential usefulness of an ENSO phase forecast (Podestá et al. 2002). Instead, a QPF for the region of interest may be required. Currently there are multiple international, regional, and national organizations that provide seasonal forecasts of regional climate, including seasonal precipitation. The multiplicity of sources, however, can prove confusing to agricultural decision-mak- ers, as there is no 'official' forecast. Because of the recent availability of seasonal forecasts, farmers do not always know the 'pedigree' of a forecast or the reliability of a given source.

\subsubsection{Changes in management decisions for alternative climate scenarios}

In previous sections we identified climate sensitive decisions and climate information needs. However, effective use of climate information requires that decision-makers be willing to change their decisions in response to a forecast (Hansen 2002). In the decision exercise, advisors were first asked to define soybean management based on climatological information only (i.e. without a climate forecast) and, subsequently, how they would adapt this management in response to various climate forecasts. Responses from the advisors provide a realistic description of potential forecast use, and are useful to derive preliminary estimates of the economic value of forecasts.

The advisors showed strong consensus on the preferred soybean management based on historical or climatological information. The CM decisions involved a mix of about 40 and $60 \%$ of the farm area sown with short- and long-cycle soybean varieties, respectively, both genotypes planted in the first week of November, with a row spacing of $0.52 \mathrm{~m}$, a sowing density of 320 plants $\mathrm{m}^{-2}$, and fertilized with $25 \mathrm{~kg} \mathrm{ha}^{-1}$ of $\mathrm{P}$. These results are consistent with 2002-2005 records of actual soybean management by AACREA farmers of both study areas. Of a total of 750 plots listed in these records, about $64 \%$ were sown with long-cycle soybean varieties while short-cycle varieties were used in the remaining $32 \%$ of plots. Similarly, more than $70 \%$ of plots were sown during the first week of November, and $95 \%$ of the cases involved a row spacing of $0.52 \mathrm{~m}$ (Technological Area of AACREA, pers. comm.).

Table 2. Relevance of specific climate information (rain and temperature forecasts) for the studied soybean management decisions. (C) Consensus that the forecast information is relevant; (NC) no consensus about the relevance of the forecast information; (-) consensus that the forecast information is not relevant

\begin{tabular}{|c|c|c|c|c|c|}
\hline \multirow{3}{*}{ Decision } & \multirow{2}{*}{\multicolumn{4}{|c|}{ - Rain for Forecast }} & \multirow{3}{*}{$\begin{array}{l}\text { Temperatures for } \\
\text { Nov/Dec/Jan }\end{array}$} \\
\hline & & & & & \\
\hline & Sept/Oct & Nov/Dec & Jan/Feb & Mar/Apr & \\
\hline $\begin{array}{l}\text { Land allocated } \\
\text { to soybean }\end{array}$ & - & - & - & - & - \\
\hline Sowing date & $\mathrm{C}$ & $\mathrm{C}$ & $\mathrm{C}$ & $\mathrm{C}$ & - \\
\hline Genotype selection & - & $\mathrm{C}$ & $\mathrm{C}$ & $\mathrm{C}$ & - \\
\hline Row spacing & - & $\mathrm{NC}$ & $\mathrm{NC}$ & $\mathrm{NC}$ & - \\
\hline Sowing density & - & - & - & - & - \\
\hline$P$ fertilizer rate & - & - & - & - & - \\
\hline
\end{tabular}


When presented with different seasonal climate scenarios, most advisors modified their CM decisions. Advisors consistently modified sowing date and the mix of genotypes (Table 3), although some advisors also changed row spacing, sowing density, or land allocation. We stress that, in all cases, the responses to each climate scenario always involved a mix of genotypes or sowing dates; none of the advisors allocated the entire area to one genotype or selected a single sowing date in response to a forecast. Subsequent discussions revealed that this diversification is intended to manage the probabilistic nature of climate forecasts (i.e. conditions predicted as most likely may not actually materialize) and risks associated with the high interannual climate variability in the region.

Most advisors changed their decisions in response to a La Niña forecast (dry spring and summer) but, in contrast, did not change their decisions after receiving an El Niño forecast. This suggests a mainly defensive response: the advisors' preference is to avoid negative impacts rather than capitalize on favorable conditions. Such defensive behavior is often observed in areas with near-optimal resource conditions like those in Pergamino (Letson et al. 2005). Furthermore, the lack of pro-active behavior after receiving an El Niño forecast may be related to the negligible impacts of El Niño phases on soybean yields (Podestá et al. 1999). The QPF also triggered changes by many of the respondents, although there was little consensus on the nature of these changes, perhaps because conditions predicted (wet November and December followed by dry January and February) were not consistent throughout the crop cycle. Table 4 shows the most representative strategies selected by the advisors for each climate scenario in the decision exercise.

Advisors showed consensus on the soybean genotypes selected for each ENSO phase. Most advisors

Table 3. Proportion of advisors changing each soybean management decision under the 3 different climate forecasts presented in the decision exercise $(n=17)$. Initial climatological management decisions used as base. See Section 3.1 for a description of the 3 climate forecasts. QPF: quantitative precipitation forecast

\begin{tabular}{|c|c|c|c|}
\hline \multirow[t]{2}{*}{ Decision } & \multicolumn{3}{|c|}{$\begin{array}{c}\text { Proportion of decision changes } \\
\text { per forecast (\%) }\end{array}$} \\
\hline & El Niño & La Niña & QPF \\
\hline Genotype selection & 58.8 & 94.1 & 82.4 \\
\hline Sowing date & 47.0 & 58.8 & 94.1 \\
\hline Row spacing & 17.7 & 11.8 & 17.7 \\
\hline Sowing density & 5.9 & 11.8 & 5.9 \\
\hline $\begin{array}{l}\text { Land allocated } \\
\text { to soybean }\end{array}$ & 0 & 5.9 & 11.8 \\
\hline$P$ fertilizer rate & 0 & 0 & 0 \\
\hline
\end{tabular}

increased the proportion of long-cycle genotypes in La Niña, whereas the opposite action was adopted for El Niño events (Table 4). Subsequent discussion suggested that both the advisors' perceptions of ENSO impacts on local climate and agronomical criteria (e.g. long-cycle varieties are preferred for unfavorable conditions) are behind these responses. In contrast to genotype selection, the choice of sowing dates conditioned by the ENSO phase varied widely among the advisors. Although most advisors changed genotype and sowing date in response to the QPF, selected strategies also varied considerably among advisors (Table 4). Discussions after the decision exercise revealed that different agronomical criteria are involved in advisors' responses, possibly explaining the differences in strategies selected under the same climate scenario.

\subsection{Economic outcomes of climate forecast use}

Simulated soybean yields and information about costs and prices were used to estimate economic outcomes for a wide range of soybean managements (treatments) and for each climate scenario. Net profits (averaged for all treatments) were higher for El Niño events (169 $\$ \mathrm{ha}^{-1}$ ) than for either the climatological scenario (161 $\$ \mathrm{ha}^{-1}$ ) or La Niña events (132 $\$ \mathrm{ha}^{-1}$ ). These results are consistent with the typical ENSO signal on rainfall in the Pergamino area (Podestá et al. 1999). For the QPF, average net profit (140\$ ha-1) was higher than for La Niña, but lower than for El Niño and the CM scenarios.

The existence of management options that show an interaction with climate scenarios allows adaptation to expected climate conditions. Simulated soybean treatments that maximized average net profit were different for the different climate scenarios. Within each climate scenario, the simulated treatments showed significant differences in the net profits. We remind readers that the treatments considered were not prescriptive or 'optimal' responses but, rather, encompassed the managements actually selected by regional advisors.

In response to the various climate scenarios presented, advisors always selected strategies that combined 2 or more treatments. There were large differences among advisors in the economic results achieved by the strategies selected for each climate scenario. Some advisors achieved higher economic results (using the CM decisions as a reference) by adapting soybean management to expected climate conditions, whereas others experienced lower profits as an outcome of their changes. In the paragraphs below, we describe the best treatment for each climate scenario, 

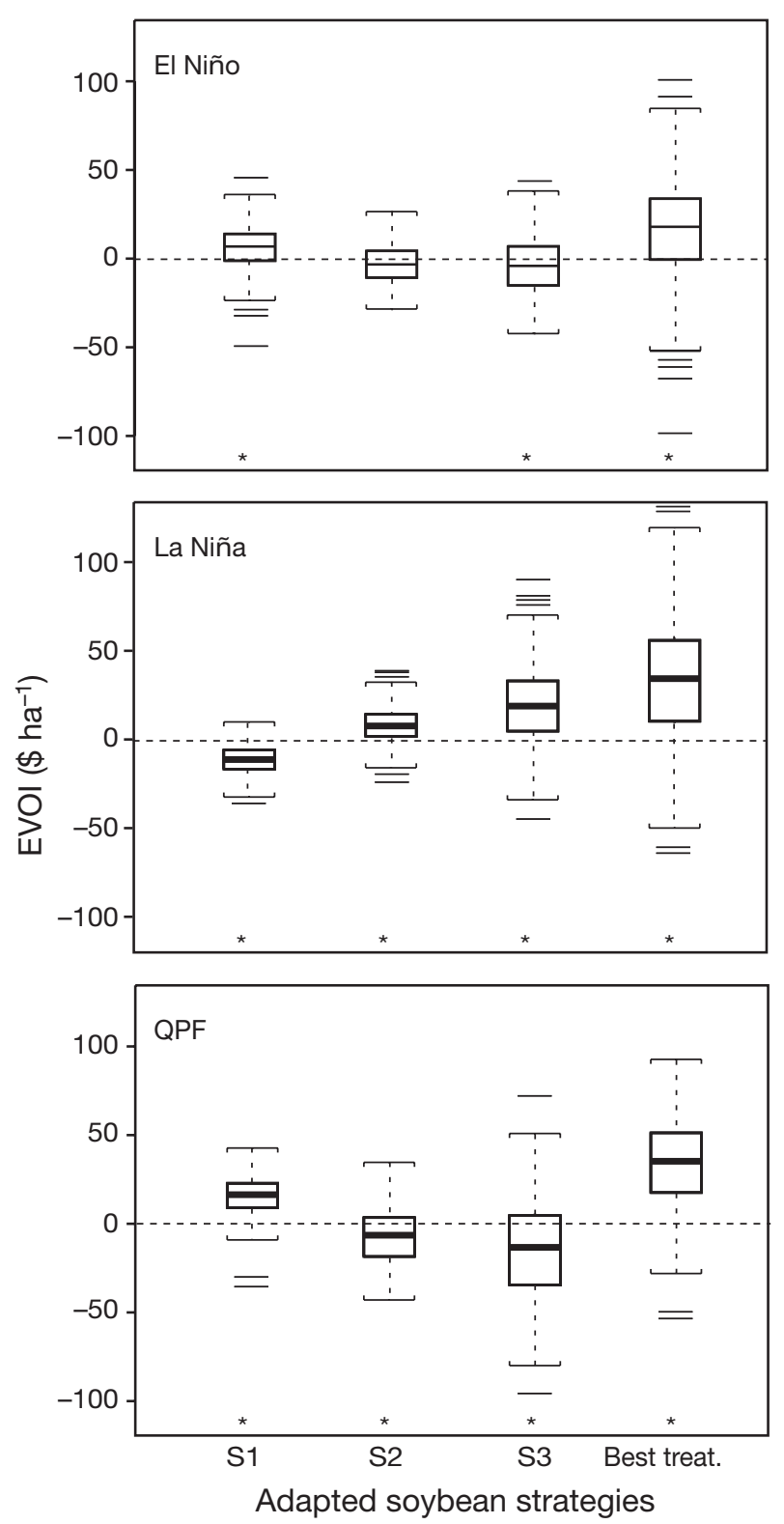

Fig. 2. Differences among economic results achieved (EVOI; Eq. 2) using the adapted soybean management strategies (S1, S2, S3; Table 4) and the CM for each climate scenario (El Niño, La Niña, QPF). 'Best treat.': simulation treatment that maximized average net profit under each climate scenario. $\left({ }^{*}\right)$ Statistically significant differences $(\mathrm{p}<0.05)$. Box: 25th and 75th percentiles; bars inside box: median values; whiskers: 5th and 95th percentiles; horizontal lines outside boxplots: outliers

bean management strategies in response to expected climate.

Despite the willingness to adapt soybean management to expected climate, our results show that responses to seasonal forecasts are incremental, that is, involve small deviations from pre-established and accepted management practices. At the same time, even during a hypothetical decision exercise, advisors never committed to a single set of practices in response to the scenario given, even if this meant the possibility of lower profits. The clear decision to adopt diversified strategies responds to a desire to manage risks and a remaining mistrust of the performance of seasonal forecasts.

Additionally, despite the apparent opportunities for the use of seasonal climate forecasts in soybean production systems of the Pampas, we found that limitations to their effective use still remain. Two clear lessons emerge from this work. The first lesson is that there are constraints with regard to the decision making context that may reduce or eliminate the ability to respond to a climate forecast. Our interaction with advisors showed that the context in which soybean production decisions are embedded is complex, and expected climate is just one of the factors affecting decisions. For example, previous studies identified land allocation decisions as the main way to extract value from climate forecasts (Messina et al. 1999, Mjelde et al. 1999). Nevertheless, our advisors stated that land allocation is strongly influenced by non-climatic factors such as crop rotation scheme, farm soil quality, and cereals/oilseeds prices. Therefore, advisors did not change or changed only slightly the land allocation in response to climate forecasts (Table 3) and did not extract value from climate forecasts for this decision. Our findings reinforce the need to develop broad approaches to evaluate forecast use that consider the full decision context and explore a realistic range of adaptive options (Eakin 2000, Hammer et al. 2001, Jochec et al. 2001, Ziervogel \& Calder 2003, Stewart et al. 2004).

The second lesson reinforces the previous findings - that the mere dissemination of a climate forecast will not necessarily produce useful results. Our simulations showed that changes adopted by advisors in response to hypothetical climate scenarios resulted in a wide range of outcomes. The simulated outcomes of adaptive actions chosen by advisors were in some cases more profitable than the reference management (CM) decisions (+19.6\$ ha ${ }^{-1}$ in La Niña), but in other cases less profitable (e.g. $-10.7 \$ \mathrm{ha}^{-1}$ in La Niña). The negative outcomes suggest that advisors may not be using climate information adequately in their decisions. There are at least 2 possible reasons for the apparent misapplication of climate information. (1) Advisors might not be fully aware of the climate signatures of some of the scenarios presented (i.e. they may not be aware of all the implications of a given ENSO phase for a particular regional climate). Letson et al. (2001) noted that farmers in the region had an incomplete knowledge of ENSO impacts on local cli- 
mate. Nevertheless, when advisors were presented with a scenario (the QPF) in which expected climate conditions were explicitly stated, still some advisors obtained negative results from their changed management. This leads us to consider a second possibility: (2) advisors may have difficulties in anticipating the agronomical outcomes of changing management decisions in response to a climate forecast. Unfortunately, our experimental design does not allow us to identify which of these possibilities (or both) may lead to maladaptive actions. We hope to explore further this issue in subsequent work.

Improving the use of climate information in the pampas region will require addressing the possible reasons leading to negative outcomes. This is even more critical when advisors are involved, given their role in the definition of farmers' production strategies and in the use of new information (as climate forecasts). The possible lack of knowledge or incorrect perceptions about regional climate may be addressed by assessing the advisors' mental models of climate variability (Morgan et al. 1992) and by designing appropriate outreach interventions (Klopper et al. 2006). Uncertainty about complex relationships between agronomic decisions and environmental factors can be addressed through the use of tools to evaluate possible outcomes of alternative actions (Hammer et al. 2001).

Lessons learned in this work confirm and reinforce previous findings in similar studies (e.g. Meinke \& Stone 1997, Hammer et al. 2001, Patt \& Gwata 2002), However, results from southeastern South America are interesting in their own right because this region differs from locations such as Africa or Australia, where most of the studies on use of climate forecasts in agriculture have been focused. The ENSO signal that provides most of the seasonal climate predictability in the pampas region is less marked than in Australia. In addition, there is significant variability among ENSO events of the same kind. Agricultural production systems in the pampas region are more intensive and technologically advanced, and also considerably more complex than most African systems. Under these conditions, the farmer's response to climate forecasts are not obvious. This case study exposed the difficulties highly-trained crop consultants had in anticipating the agronomical outcomes of changing the management of a complex system in response to uncertain climate forecast. Our results suggest that for climate information to be used effectively, decision makers need to understand the sources and impacts of climate variability, and to develop skills in using tools that help them evaluate possible outcomes of alternative actions and cope with forecast uncertainties.
Acknowledgements. Financial support was provided by the US National Science Foundation (Biocomplexity in the Environment, Grant 0119851). We thank AACREA technical advisors from northern Buenos Aires and southern Santa Fé for their time and valuable help. We also thank S. Perelman, CENTRO de Estudios Sociales y Ambientales (Argentina), E. Weber, J. Mercau and F. Ruiz Toranzo for their helpful comments. F.E.B. has a PhD scholarship from, and E.H.S. is member of, CONICET (Argentina's Science Research Council).

\section{LITERATURE CITED}

Bert FE, Satorre EH, Ruiz Toranzo F, Podestá G (2006) Climatic information and decision-making in maize crop production systems of the Argentinean Pampas. Agric Syst 88:106-204

Barnston AG, Kumar A, Goddard L, Hoerling MP (2005) Improving seasonal prediction practices through attribution of climate variability. Bull Am Meteorol Soc 86: $59-72$

Boote KJ, Jones JW (1998) Simulation of crop growth: CROPGRO model. In: Peart RM, Curry RB (eds) Agricultural systems modeling and simulation. Marcel Dekker, New York, p 651-692

Broad K, Agrawala S (2000) The Ethiopia famine: uses and limits of seasonal climate forecasts. Science 289: 1693-1694

Eakin H (2000) Smallholder maize production and climatic risk: a case study from Mexico. Clim Change 45:19-36

Goddard L, Barnston AG, Mason SJ (2003) Evaluation of the IRI "net assessment" seasonal climate forecasts 1997-2001. Bull Am Meteorol Soc 84:1761-1781

Grimm AM, Barros VR, Doyle ME (2000) Climate variability in southern South America associated with El Niño and La Niña events. J Clim 13:53-58

Grondona MO, Podestá GP, Bidegain M, Marino M, Hordij H (2000) A stochastic precipitation weather generator conditioned on ENSO phase: a case study in southeastern South America. J Clim 12:2973-2986

Hall AJ, Rebella CM, Ghersa CM, Culot JPH (1992) Field crops systems of the Pampas. In: Pearson CJ, (ed) Field crops systems: ecosystems of the world, Vol 18. Elsevier, Amsterdam, p 413-449

Hammer GL, Hansen JW, Philips J, Mjelde JW, Hill HSJ, Love A, Potgieter A (2001) Advances in application of climate prediction in agriculture. Agric Syst 70:515-533

Hansen JW (2002) Realizing the potential benefits of the climate prediction to agriculture: issues, approaches, challenges. Agric Syst 74:309-330

Jochec KG, Mjelde JW, Lee AC, Conner JR (2001) Use of seasonal climate forecasts in rangeland-based livestock operations in west Texas. J Appl Meteorol 40:1629-1639

Jones JW, Tsuji G, Hoogenboom G, Hunt L and 5 others (1998) Decision support system for agrotechnology transfer. In: Tsuji G, Hoogenboom G, Thornton P (eds) Understanding options for agricultural production. Kluwer, Dordrecht, p 157-177

Jones JW, Hansen JW, Royce FS, Messina CD (2000) Potential benefits of climate forecasting to agriculture. Agric Ecosyst Environ 82:169-184

Klopper E, Vogel CH, Landman WA (2006) Seasonal climate forecasts-potential agricultural-risk management tools? Clim Change 76:73-90

Letson D, Llovet I, Podestá GP, Royce FS, Brescia F, Lema V, Parellada D (2001) User perspectives of climate forecasts: 
crop producers in Pergamino, Argentina. Clim Res 19: $57-67$

Letson D, Podestá GP, Messina CD, Ferreyra RA (2005) ENSO forecast value, variable climate and stochastic prices. Clim Change 69:163-196

Mason SJ, Joubert AM, Cosijn C, Crimp SJ (1996) Review of seasonal forecasting techniques and their applicability to southern Africa. Water SA 22:203-209

Mason SJ, Goddard L, Graham NE, Yulaeva E, Sun L, Arkin PA (1999) The IRI seasonal climate prediction system and the 1997/98 El Niño event. Bull Am Meteorol Soc 80: 1853-1873

Meinke H, Stone RC (1997) On tactical crop management using seasonal climate forecasts and simulation modeling: a case study for wheat. Sci Agric Piracicaba 54:121-129

Meinke H, Stone RC (2005) Seasonal and interannual climate forecasting: the new tools for increasing preparedness to climate variability in agricultural planning and operations. Clim Change 70:221-253

Meira S, Guevara E (1997) Application of SOYGRO in Argentina. In: Kropff MJ, Teng PS, Aggrawal PK, Bouman J, Jones JW, Van Laar HH (eds) Applications of systems approaches at field level, Vol 2. Kluwer, Dordrecht, p 235-242

Mercau JL, Dardanelli JL, Collino DJ, Andriani JM, Irigoyen A, Satorre EH (2007) Predicting on-farm soybean yields in the pampas using CROPGRO-soybean. Field Crops Res 100:200-209

Messina CD, Hansen JW, Hall A (1999) Land allocation conditioned on ENSO phases in the Argentine Pampas. Agric Syst 60:197-212

Mjelde JW, Thompson TN, Nixon CJ, Lamb PJ (1999) Utilizing a farm-level decision model to help prioritize future climate prediction research needs. Meteorol Appl 4: 161-170

Montecinos A, Diaz A, Aceituno P (2000) Seasonal diagnostics and predictability of rainfall in subtropical South America based on Tropical Pacific SST. J Clim 13:746-758

Morgan MG, Fischhoff B, Bostron A, Lave L, Atman CJ (1992) Communicating risk to the public: first, learn what people know and believe. Environ Sci Technol 26:2048-2056

Murphy S, Washington R, Downing TE, Martin RV and 5 others (2001) Seasonal forecasting for climate hazards: prospects and responses. Nat Hazards 23:171-196

Orlove B, Tosteson J (1999) Case studies in the application of ENSO forecasts: lessons from Australia, Peru, Brazil, Ethiopia, and Zimbabwe. Environmental politics working papers series. Institute of International Studies, University of California, Berkeley

Patt A, Gwata C (2002) Effective seasonal climate forecast applications: examing constraints for subsistence farmers in Zimbawe. Global Environ Change 12:185-195

Editorial responsibility: Mauricio Lima, Santiago, Chile
Phillips JG, Makaudze E, Unganai L (2001) Current and potential use of climate forecasts for resource-poor farmers in Zimbabwe. Impacts of El Niño and climate variability on agriculture. Am Soc Agron Spec Publ 63: $87-100$

Podestá GP, Messina CD, Grondona MO, Magrín GO (1999) Associations between grain crop yield in central-eastern Argentina and El Niño southern oscillation. J Appl Meteorol 38:1488-1498

Podestá GP, Letson D, Messina CD, Royce F and 6 others (2002) Use of ENSO-related climate information in agricultural decision making in Argentina: a pilot experience. Agric Syst 74:371-392

Pulwarty RS, Redmond K (1997) Climate and salmon restoration in the Columbia River Basin: the role and usability of seasonal forecasts. Bull Am Meteorol Soc 78:381-397

Richardson CW (1981) Stochastic simulation of daily precipitation, temperature and solar radiation. Water Resour Res $17: 182-190$

Roncoli C, Ingram K, Kirshen P (2001) The costs and risks of coping with drought: livelihood impacts and farmers' responses in Burkina Faso. Clim Res 19:119-132

Ropelewski CF, Halpert MS (1987) Global and regional scale patterns associated with the El Niño southern oscillation. Mon Weather Review 115:1606-1626

Ropelewski CF, Halpert MS (1989) Precipitation patterns associated with the high index phase of the southern oscillation. J Clim 13:35-38

Ropelewski CF, Halpert MS (1996) Quantifying southern oscillation - precipitation relationships. J Clim 9:1043-1059

Satorre EH (2005) Cambios tecnológicos en la agricultura actual. Ciencia Hoy 15:24-31

Stern PC, Easterling WE (eds) (1999) Making climate forecasts matter. National Academy Press, Washington, DC

Stewart TR (1997) Forecast value: descriptive decision studies. In: Katz RW, Murphy AH (eds) Economic value of weather and climate forecasts. Cambridge University Press, Cambridge, p 147-181

Stewart TR, Pielke R Jr, Nath R (2004) Understanding user decision making and the value of improved precipitation forecasts. Lessons from a case study. Bull Am Meteorol Soc 85:223-235

Travasso MI, Magrín GO, Rodríguez GR (2003) Relations between sea-surface temperature and crop yields in Argentina. Int J Climatol 23:1655-1672

Wilks D (1997) Forecast value: prescriptive decision studies. In: Katz RW, Murphy AH (eds) Economic value of weather and climate forecasts. Cambridge University Press, Cambridge, p 109-145

Ziervogel G, Calder R (2003) Climate variability and rural livelihoods: assessing the impact of seasonal climate forecasts in Lesotho. Area 35:403-417

Submitted: June 28, 2006; Accepted: January 2, 2007

Proofs received from author(s): February 16, 2007 